\title{
Underground measurements of short-period seismic noise
}

\author{
MI. BÂTH
}

\author{
Ricevuto il 10 Febbraio 1966
}

\begin{abstract}
SUmarr. - Seismic noise in the frequency range of $8-33$ cycles/sec has been recorded in three mines (Haggruvan, Idkerberget, Stripa) in central Sweden at different levels down to about $750 \mathrm{~m}$. As an average it is found that the noise amplitude decreases to 25 percent of its surface value at a depth of $50 \mathrm{~m}$, to 13 percent at $100 \mathrm{~m}$, to 6 percent at $200 \mathrm{~m}$ depth, and is less than 1 percent of the surface value at depths exceeding $500 \mathrm{~m}$. Individual variations in these numbers amount to about 100 percent in average, which could be explained by variations in rock properties, wave periods and distance and direction to noise sources. The source of the noise studied was various surface disturbances, mainly traffic. The obtained amplitudedepth cliagrams suggest an interpretation in terms of bolly waves rather than surface waves, and the depth effect is mainly to be explained as due to increasing distance from the noise source.
\end{abstract}

Riassunto. - Disturbi sismici con frequenze dell'ordine di $8-33$ cicli sec. sono stati registrati in tre miniere (Haggruvan, Idkerberget, Stripa) nella Svezia centrale a diverse quote fino ad oltre i $750 \mathrm{~m}$. Come media si è trovato che l'ampiezza del disturbo si riduce al $25 \%$ del valore corrispondente in superficie alla profondita di $50 \mathrm{~m}$, al $13 \%$ a $100 \mathrm{~m}$, al $6 \%$ a $200 \mathrm{~m}$, ed e minore dell' $1 \%$ a profondità superiori dei $500 \mathrm{~m}$.

Variazioni singole in questi valori ammontano a circa il $100 \%$ in media, il che potrebbe essere spiegato da variazioni nelle proprietà della roccia, dai periodi dell'onda e dalla distanza e direzione rispetto alla sorgente del disturbo. La sorgente del disturbo è stata studiata in superficie, soprattutto per quanto concerne il traffico. Il diagramma ampiezza-profondità, suggerisce un'interpretazione di onde in spaziali piuttosto che superficiali, e l'effetto profondità si può spiegare soprattutto come dovuto allaumentare della distanza dalla sorgente del disturbo.

\section{INTRODUCTION.}

The problem to select sensitive sites for the location of seismograph stations has always been of great significance in seismology. In recent 
years, this problem has got increased importance in connection with recordings of nuclear explosions, where the requirements for high sensitivity are very stringent. The main limitation to the effectiveness of seismic recordings usually derives from various noise sources. The source of seismic noise (microseisms) is to be found on the earth's surface, and this is true for the whole period range of microseisms, from those of periods above $20 \mathrm{sec}$ down to local noise with periods of around $0.1 \mathrm{sec}$ or less. There are essentially two ways to avoid noise sources: either to search for quiet places on the surface with good bedrock and far away from noise sources, or to place seismometers underground at the greatest possible distance from the surface. The first problem - the reconnaissance of surface conditions by test recordings - was studied for the Swedish territory in another paper (Bath 1965). The present paper will report some test recordings underground in three iron ore mines in central Sweden.

Our measurements concern the period range 0.03-0.13 sec (i. e. frequency range of 33-8 cycles/sec) and they concern the amplitudedepth relation in hard rock (leptite) from the surface down to depths below $700 \mathrm{~m}$. Our results are primarily of observational interest, rather than of theoretical significance. These measurements are the first of this kind in Sweden and the first reported from this part of Europe. Related measurements have been reported from Czechoslovakia (Karník and Tobyas 1961) and in several publications from the U.S.A. (see e.g. Broding and Hearn 1961, Carder 1963, Vesiac Staff 1964). In most cases, these other measurements concern lower frequencies and sedimentary rock, i.e. two facts which have to be taken into account in any comparisons of the results.

\section{Obseryational Miaterial.}

Three iron ore mines in central Sweden (Haggruvan, Idkerberget, Stripa) were selected for investigation of the noise conditions (Table I). The measurements were not made on the iron ore itself but in every case on the surrounding rock. In all these mines, this rock consists of leptite. For more detailed information on the geology, the reader is referred to Magnusson, Granlund and Lundqvist (1949) and to Magnusson (1953). Our measurements are representative of conditions in hard rock, exhibiting no obvious fractures or weak zones which could influence the downward propagation of seismic waves in the fre- 
quency range we are concerned witlı. Our results also demonstrate no noticeable discontinuities or other inhomogeneities in the rock structure, with possible exception for the uppermost $100 \mathrm{~m}$.

Table I - DATA FOR THE INVESTIGATED WINES.

\begin{tabular}{|c|c|c|c|}
\hline Mine & Haggruvan (H) & Idkerberget (I) & Stripa (S) \\
\hline $\begin{array}{l}\text { Geographical } \\
\text { coordinates }\end{array}$ & $\begin{array}{l}59^{\circ} 58^{\prime} 34^{\prime \prime} \quad \mathrm{N} \\
14^{\circ} 55^{\prime} 34^{\prime \prime} \quad \mathbf{E}\end{array}$ & $\begin{array}{l}60^{\circ} 22^{\prime} 54^{\prime \prime}, \mathrm{N} \\
15^{\circ} 13^{\prime} 40^{\prime \prime} \mathrm{E}\end{array}$ & $\begin{array}{l}59^{\circ} 42^{\prime} 22^{\prime \prime}, \mathrm{N} \\
15^{\circ} 05^{\prime} 59^{\prime \prime} \mathrm{E}\end{array}$ \\
\hline $\begin{array}{l}\text { Depth levels } \\
\text { investigated (m) }\end{array}$ & $\begin{array}{l}0,35,60,120, \\
160,200,300 \\
400,500,\end{array}$ & $\begin{array}{l}0,25,50,85 \\
125,165,365 \\
500,650,750\end{array}$ & $\begin{array}{l}0,25,55,135, \\
210,310,416\end{array}$ \\
\hline $\begin{array}{l}\text { Number of test } \\
\text { recordings }\end{array}$ & 23 & 15 & 8 \\
\hline
\end{tabular}

The instruments used were a 12-channel seismic refraction equipment, described by Bath (1960). This permitted us to place the seismometers at a number of levels and to get simultaneous recordings from all these levels. The equipment was calibrated in the laboratory with shaking-table tests in comnection with these measurements and the response curves thus obtained were used in the calculation of ground amplitudes. Only the vertical component is recorded.

The field operations were performed between Aug. 19 and Sep. 8, 1965. As all three mines are still working mines, we had to select such intervals for our recordings when the mining operations were interrupted. From this point of view, abandoned mines may appear to ofier better places for investigation, but this possible advantage is more than outweighed by the fact that the access to such mines is difficult or impossible (elevators out of operation or dismantled, no safety guarantee). By courtesy of the mining company, even the electric net and pumping installations were interrupted for several intervals, to provide good measurements. It is naturally of paramount importance that the noise should originate at the surface and not within the mine at deeper levels if any reliable depth variation should be discovered.

The simultaneous measurements from the different levels must be comparable. This may be difficult to achieve, even if the response curves are well known. One factor of importance is the coupling of the seismometers to the rock. Placing all seismometers on the surface 
close to each other and with apparently equal ground coupling, it was found that the noise amplitude was $42.8 \pm 6.9$ millimicrons, i. e. a standard deviation of 16 percent. When placed at different levels, also other factors enter, such as dominance of different noise sources at different levels. Especially the surface level may often give quite different results if seismometers are spread out over a small area. Therefore, it may be useful to have several seismometer's on the surface, to gret a representative value. This was done in the Haggruvan measurements, where four seismometers were placed on the surface. Two typical records are shown in Fig. 1.

Out of the total number of 46 records, each running for a few seconds, we selected 28 isolated waves for amplitude and period measurement. Only such cases were measured where one and the same wave could be identified on all or most seismograph traces. The trace amplitudes were converted to ground amplitudes, taking the amplifier and filter settings and response curves into account. It could have been desirable to have amplitude or power spectra of the simultaneous noise from the different levels constructed from digitized records. However, our data are not suitable for the application of this technique, due to the variation in the shape of the records from one level to the next. Such spectra, if constructed from these data, would not represent exactly the same wave motion at all levels, and would therefore be difficult to use for deducing any depth variations. Therefore, in order to isolate any possible depth dependence, we had to focus our attention to single waves which could be correlated from level to level beyond any doubt. Care was taken to include waves of as many different periods as possible, and the total range covered extends from 0.03 to $0.13 \mathrm{sec}$ in period. The selection of the observations can be considered to be unbiased and more sophisticated technique would hardly improve or change our results.

\section{AMPITTUDE-DEPTIL RELATIONS AND THEIR INTERPRETATION.}

The immediate results of the measurements are compiled in Figs 2 and 3 . We have chosen to plot $\log a$ (logarithm to the base 10 and ground amplitude a expressed in units of 0.1 millimicrons) versus depth $h$ (in meters), simply for practical reasons and this choice is independent of the physical nature of the waves observed. Two conclusions are immediately obtained, unanimously supported by all investigated cases, 
$m$

$m$

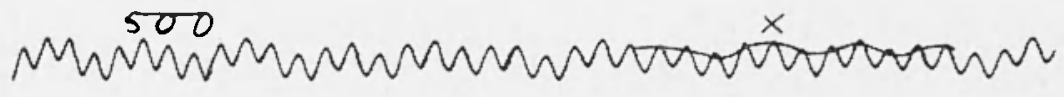
MWMWMWWWWWWMWWW

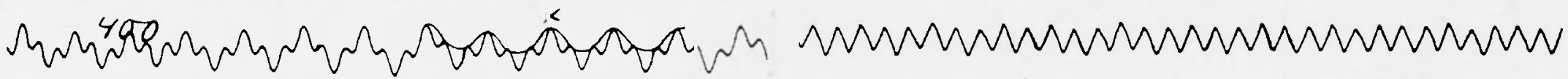

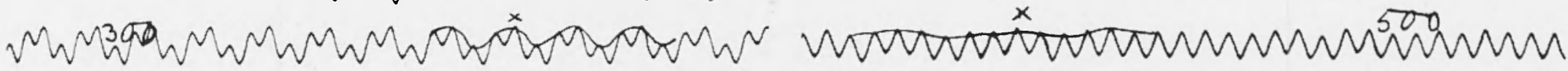

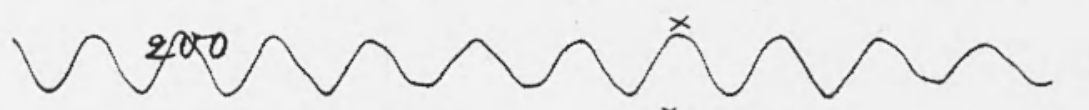

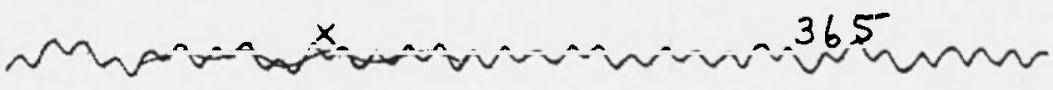

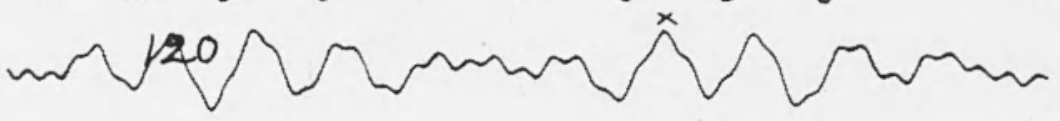
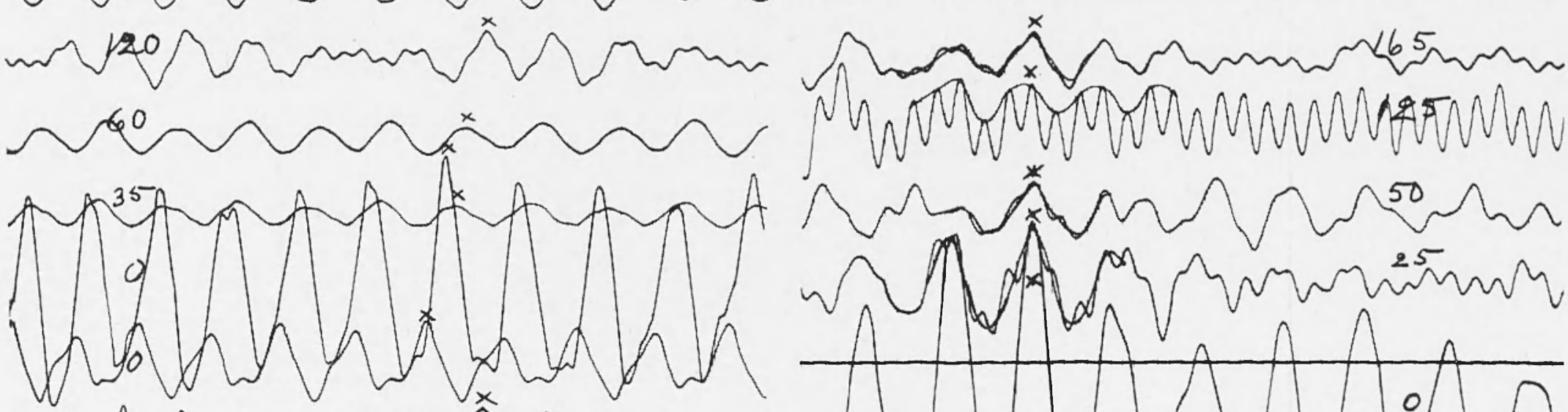

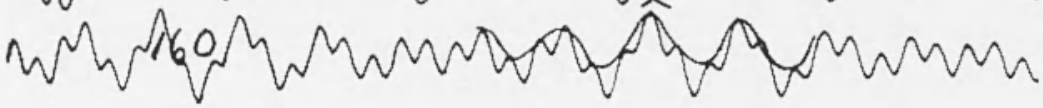

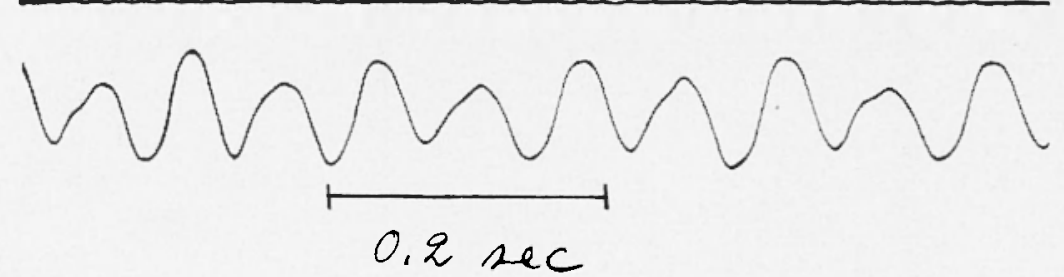

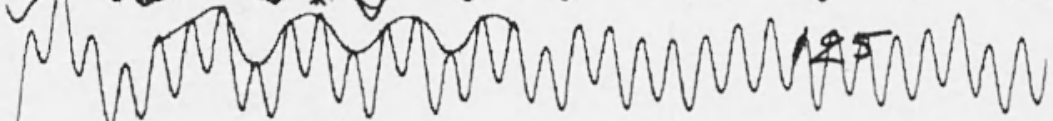

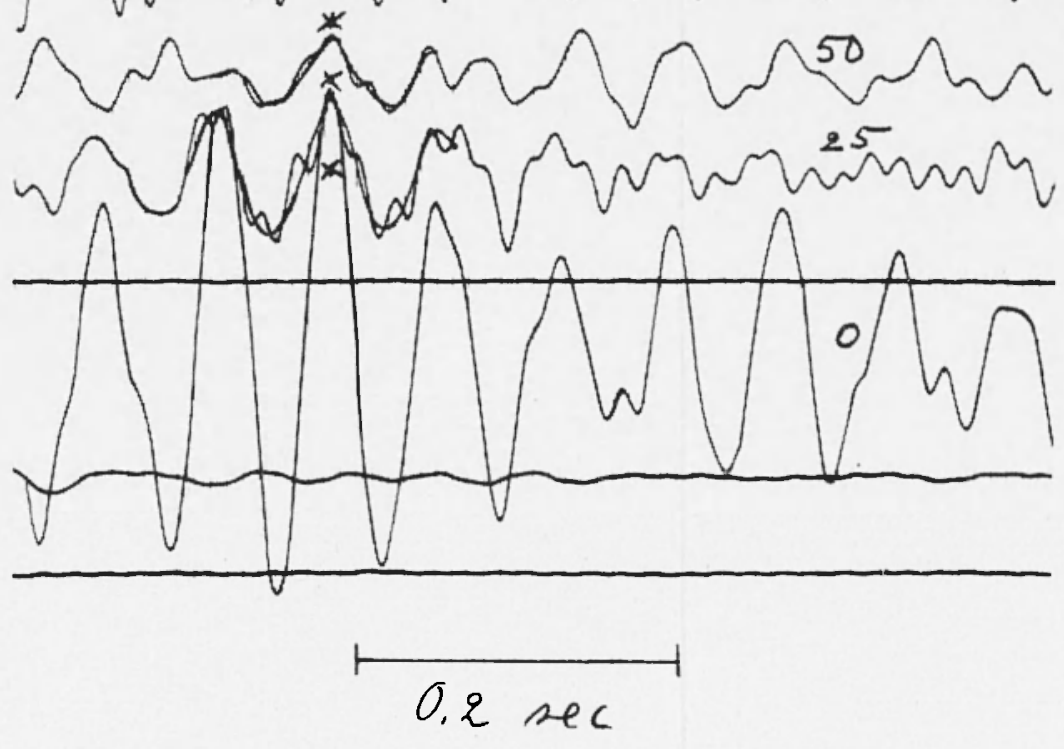

Fig. 1 - Two typical sets of records (cases $13 \mathrm{H}$ and 24 I) with depths (in Iu) given. The electric net (50 cycles/sec) is disturbing on several channels. Crosses mark the measured waves. 


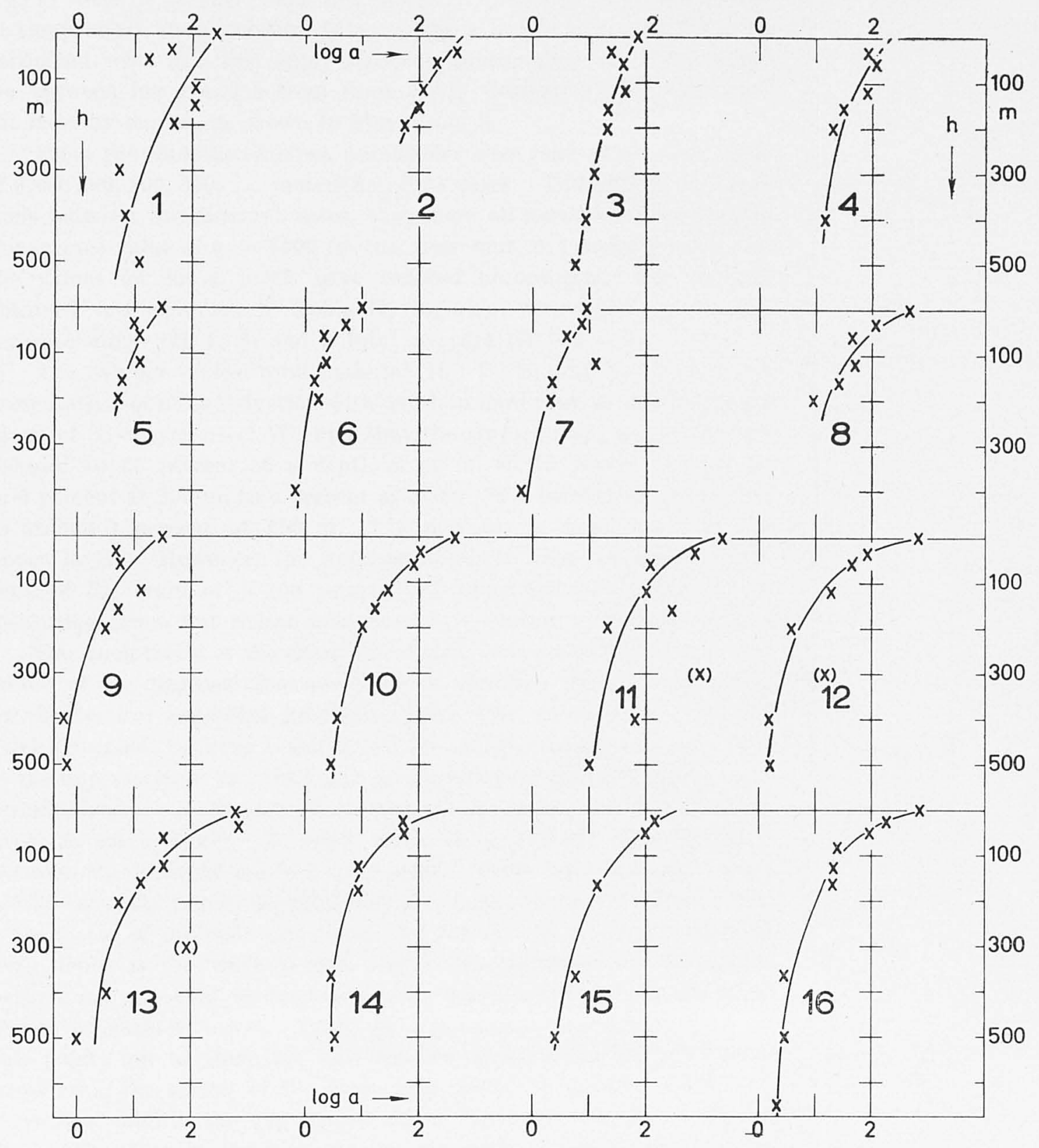

Fig. 2 - Amplitude-depth data for cases 1-16. The unit of amplitude $a$ is $0.1 \mathrm{mu}$. The crosses are the observed data.

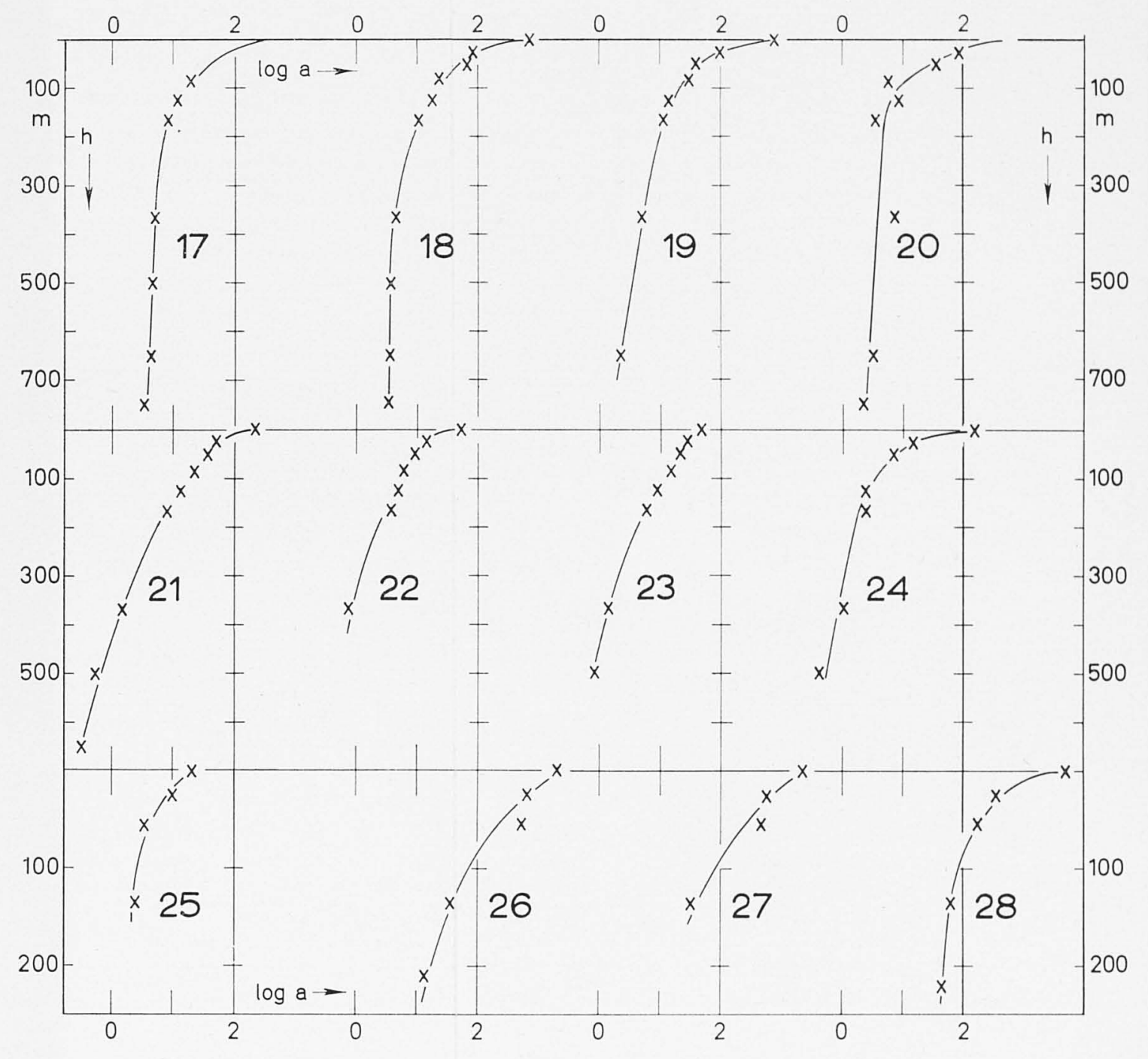

Fig. 3 - Amplitude-depth data for cases 17-28. 
i. e. 1) there is a very clear decrease of amplitude with depth, and 2 ) there is no linear relation between $\log a$ and $h$. It would not be permitted, even as a first approximation, to formulate any linear relation between $\log a$ and $h$ from these data. Instead I have smoothed the data by curves, as shown in Figs 2 and 3.

From the smoothed curves, amplitudes were read at selected levels of $0,50,100,200,300, \ldots$ meters for all 28 cases. To facilitate comparisons between the different cases, they were all normalized by putting the surface value of $a=1000$ (in the same unit, 0.1 millimicrons), and the values for lower levels were reduced accordingly. The data so obtained are compiled in Table II, together with averages for the separate mines $(H, I, S)$ and a total average $(H+I+S)$.

The average of the total material $(H+I+S)$ may be taken as representative of noise reduction with depth in hard rock in the frequency range of 33-8 cycles/sec. We find that the surface noise amplitudes are reduced to 25 percent at a depth of $50 \mathrm{~m}$, to 13 percent at $100 \mathrm{~m}$, to 6 percent at $200 \mathrm{~m}$, to 4 percent at $300 \mathrm{~m}$, to 3 percent at $400 \mathrm{~m}$, and to around 1 percent at $500 \mathrm{~m}$. The decrease is most rapid in the upper layers. However, the average numbers have standard deviations of the order of \pm 100 percent and these are not simply due to measuring error's but reflect influences of a number of factors.

One such factor is the character of rock, which could give different values of the decrease from one mine to another. This is best shown by the vertical amplitude gradients (Table III), which show relatively good agreement between $I$ and $\mathrm{S}$, but deviating values for $\mathrm{H}$, especially in the uppermost $50 \mathrm{~m}$. At I and $\mathrm{S}$, there is a significantly greater amplitude decrease in the top $50 \mathrm{~m}$ than at $\mathrm{H}$, where the decrease with depth is much slower. In lower levels $(h \geqslant 100 \mathrm{~m})$, the agreement between the different mines is very good. Truly representative values would naturally require examination of a large number of mines. Another factor of probable significance for the rate of amplitude decrease with depth is the wave period: amplitudes corresponding to shorter periods are expected to decrease faster, whether the waves are body waves or surface waves. Table IV summarizes our information on this point, but as there are now too few observations in each group consiclering the scatter of the data, only about 50 percent of the observations confirm the expectation (these data are printed in italics in Table IV). Finally, the type of noise source, its distance and direction from the mines, could be expected to influence the amplitude gradient. However, the data are inconclusive on this point. 
Table II - SUMmaRY OF AMPlitude DATa.

\begin{tabular}{|c|c|c|c|c|c|c|c|c|c|c|c|}
\hline \multirow{2}{*}{ Case } & \multirow{2}{*}{$\begin{array}{l}\text { Wave } \\
\text { period } \\
\text { sec }\end{array}$} & \multicolumn{8}{|c|}{ Normalized amplitudes $a(0.1 \mathrm{~m} \mu)$} & \multirow{2}{*}{ Noise source } & \multirow{2}{*}{$\begin{array}{c}\text { Distance }(d) \\
\text { to source } \\
\text { m }\end{array}$} \\
\hline & & $50 \mathrm{~m}$ & $100 \mathrm{~m}$ & $200 \mathrm{~m}$ & $300 \mathrm{~m}$ & $400 \mathrm{~m}$ & $500 \mathrm{~m}$ & $600 \mathrm{~m}$ & $700 \mathrm{~m}$ & & \\
\hline $1 \mathrm{H}$ & 0.06 & 504 & 280 & 99 & 50 & 28 & 18 & & & Traffic (train) & 330 \\
\hline $2 \overrightarrow{\mathrm{H}}$ & 0.03 & 447 & 251 & 100 & & & & & & \# & 330 \\
\hline $3 \mathrm{H}$ & 0.13 & 634 & 451 & 282 & 183 & 111 & 79 & & & $"$ & 330 \\
\hline $4 \mathrm{H}$ & 0.08 & 500 & 280 & 140 & 100 & 70 & & & & $\eta$ & 20 \\
\hline $5 \mathrm{H}$ & 0.10 & 500 & 312 & 156 & & & & & & (bus) & 150 \\
\hline $6 \mathrm{H}$ & 0.06 & 400 & 220 & 130 & 90 & 70 & & & & (train) & 330 \\
\hline $7 \mathrm{H}$ & 0.10 & 560 & 320 & 180 & 110 & 80 & & & & , & 330 \\
\hline $8 \mathrm{H}$ & 0.05 & 199 & 89 & 36 & & & & & & $n$ & 20 \\
\hline $9 \mathrm{H}$ & 0.10 & 343 & 156 & 63 & 41 & 25 & 19 & & & 11 & 20 \\
\hline $10 \mathrm{H}$ & 0.08 & 224 & 80 & 28 & 14 & 10 & 8 & & & $n$ & 20 \\
\hline $11 \mathrm{H}$ & 0.06 & 141 & 56 & 20 & 10 & 7 & 6 & & & $n$ & 20 \\
\hline $12 \mathrm{H}$ & 0.07 & 71 & 25 & 8 & 4 & 3 & 2 & & & Compressor & 0 \\
\hline $13 \mathrm{H}$ & 0.07 & 141 & 44 & 10 & 5 & 3 & 3 & & & Traffic (train) & 330 \\
\hline $14 \mathrm{I}$ & 0.09 & 127 & 44 & 18 & 11 & 10 & 9 & & & Compressor & 0 \\
\hline $15 \bar{I}$ & 0.08 & 250 & 111 & 35 & 18 & 11 & 9 & & & "1 & 0 \\
\hline $16 \mathrm{I}$ & 0.09 & 112 & 40 & 14 & 8 & 5 & 4 & 3 & 3 & Traffic (bus) & 50 \\
\hline $17 \mathrm{I}$ & 0.12 & 127 & 51 & 22 & 16 & 14 & 13 & 13 & 11 & $"$ (truck) & 50 \\
\hline $18 \mathrm{I}$ & 0.11 & 79 & 32 & 13 & 8 & 6 & 5 & 5 & 5 & " & 50 \\
\hline $19 \mathrm{I}$ & 0.11 & 57 & 25 & 11 & 8 & 6 & 4 & 3 & & (tractor & 50 \\
\hline $20 \mathrm{I}$ & 0.11 & 70 & 20 & 11 & 10 & 9 & 8 & 7 & 6 & (truck) & 50 \\
\hline $21 \mathrm{I}$ & 0.09 & 160 & 80 & 25 & 11 & 6 & 3 & 2 & & $n$ & 50 \\
\hline $22 \mathrm{I}$ & 0.09 & 178 & 100 & 44 & 22 & 14 & & & & $(\mathrm{car})$ & 0 \\
\hline $23 \mathrm{I}$ & 0.07 & 444 & 244 & 89 & 44 & 29 & 18 & & & $n$ & 0 \\
\hline $24 \mathrm{I}$ & 0.07 & 50 & 23 & 10 & 8 & 5 & 4 & & & $n$ & 0 \\
\hline $25 \mathrm{~S}$ & 0.10 & 250 & 125 & & & & & & & Wind & $\ldots$ \\
\hline $26 \mathrm{~S}$ & 0.05 & 126 & 36 & 9 & & & & & & Traffic (truck) & 25 \\
\hline $27 \mathrm{~S}$ & 0.06 & 141 & 35 & & & & & & & $n$ & 25 \\
\hline $28 \mathrm{~S}$ & 0.06 & 63 & 25 & 16 & & & & & & $n$ & 25 \\
\hline $\mathrm{H}$ & & 359 & 197 & 96 & 61 & 41 & 19 & & & & \\
\hline $\mathrm{I}$ & & 150 & 70 & 27 & 15 & 10 & 8 & 6 & 6 & & \\
\hline $\mathrm{S}$ & & 145 & 55 & 13 & & & & & & & \\
\hline $\mathrm{H}+\mathrm{I}+\mathrm{S}$ & & 246 & 127 & 60 & 37 & 25 & 12 & 6 & 6 & & \\
\hline
\end{tabular}


Table III - Average Gradients $\frac{\mathrm{d} \log _{r} a}{\mathrm{~d} h}$ For given depti intervals, FOR EACI MINE SEPARATELY AND FOR THE TOTAL MATERIAL. (The units are $0.1 \mathrm{~m} \mu$ for $a$ and $100 \mathrm{~m}$ for $h$. The errors given are standard deviations of single observations and the number of observations is giren in parenthesis after each value).

\begin{tabular}{|c|c|c|c|c|}
\hline $\begin{array}{c}\text { Depth } \\
\text { interval (m) }\end{array}$ & II & I & 8 & $H+I+S$ \\
\hline $0-50$ & $1.04 \pm 0.56(13)$ & $1.82 \pm 0.54$ (11) & $1.78 \pm 0.43$ (4) & $1.45 \pm 0.66(28)$ \\
\hline $50-100$ & $0.63 \pm 0.21 \quad(13)$ & $0.75 \pm 0.17$ (11) & $0.93 \pm 0.24$ (4) & $0.72 \pm 0.22$ \\
\hline $100-200$ & $0.38 \pm 0.12(13)$ & $0.40+0.07$ (11) & $0.40 \pm 0.20(2)$ & $0.39 \pm 0.11(26)$ \\
\hline $200-300$ & $0.24 \pm 0.06(10)$ & $0.23 \pm 0.07$ (11) & & $0.23 \pm 0.07$ (21) \\
\hline $300-400$ & $0.17 \pm 0.04(10)$ & $0.15 \pm 0.08$ (11) & & $0.16 \pm 0.06(21)$ \\
\hline $400-500$ & $0.14 \pm 0.03(7)$ & $0.12 \pm 0.07(10)$ & & $0.13 \pm 0.06(17)$ \\
\hline $500-600$ & & $0.08 \pm 0.07$ (6) & & $0.08 \pm 0.07 \quad(6)$ \\
\hline $600-700$ & & $0.04 \pm 0.02$ & & $0.04+0.02$ \\
\hline
\end{tabular}

Table IV - Average gradients $\frac{d \log a}{\mathrm{~d} h}$ For given deptil intervala, For haGgRUVAN (H) AND IDKERBERGET (I), AND FOR GIVEN WAVE PEIRIODS. (Same units as in Table III).

\begin{tabular}{|c|c|c|c|c|c|}
\hline $\begin{array}{c}\text { Depth interval } \\
\mathrm{m}\end{array}$ & $\begin{array}{c}0.06 \\
\mathrm{sec}\end{array}$ & $\begin{array}{c}0.07 \\
\text { sec }\end{array}$ & $\begin{array}{c}\text { H } \\
0.08 \\
\text { sec }\end{array}$ & $\begin{array}{c}0.10 \\
\text { sec }\end{array}$ & $\begin{array}{c}0.13 \\
\mathrm{sec}\end{array}$ \\
\hline $\begin{array}{c}0-50 \\
50-100 \\
100-200 \\
200-300 \\
300-400 \\
400-500\end{array}$ & $\begin{array}{l}1.03 \\
0.60 \\
0.38 \\
0.25 \\
0.17 \\
0.10\end{array}$ & $\begin{array}{l}2.00 \\
0.95 \\
0.58 \\
0.28 \\
0.18 \\
0.13\end{array}$ & $\begin{array}{l}0.95 \\
0.70 \\
0.35 \\
0.23 \\
0.15 \\
0.10\end{array}$ & $\begin{array}{l}0.67 \\
0.53 \\
0.32 \\
0.20 \\
0.18 \\
0.15\end{array}$ & $\begin{array}{l}0.40 \\
0.30 \\
0.20 \\
0.20 \\
0.20 \\
0.15\end{array}$ \\
\hline Depth interval & 0.07 & 0.08 & $\begin{array}{c}\text { I } \\
0.09 \\
\end{array}$ & 0.11 & 0.12 \\
\hline $\begin{array}{c}0-50 \\
50-100 \\
100-200 \\
200-300 \\
300-400 \\
400-500\end{array}$ & $\begin{array}{l}1.65 \\
0.60 \\
0.40 \\
0.20 \\
0.20 \\
0.18\end{array}$ & $\begin{array}{l}1.20 \\
0.70 \\
0.50 \\
0.30 \\
0.20 \\
0.10\end{array}$ & $\begin{array}{l}1.70 \\
0.73 \\
0.43 \\
0.28 \\
0.19 \\
0.13\end{array}$ & $\begin{array}{l}2.30 \\
0.87 \\
0.33 \\
0.20 \\
0.10 \\
0.10\end{array}$ & $\begin{array}{l}1.80 \\
0.80 \\
0.35 \\
0.15 \\
0.05 \\
0.03\end{array}$ \\
\hline
\end{tabular}


As we recorded only the vertical component, the records give no immediate information on the type of waves observed. However, the observed amplitude-depth relation definitely favours an explanation in terms of body waves and not surface waves. This result, which we shall now demonstrate, differs from most other related investigations which seem to favour an explanation in terms of Rayleigh waves.

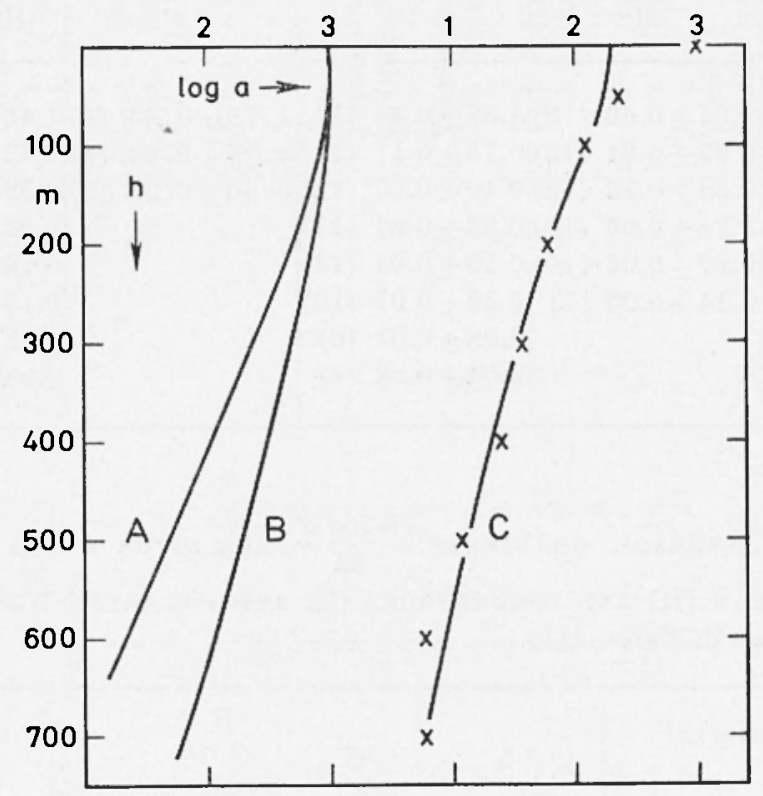

Fig. 4 - Theoretical interpretation of the average ( $\mathrm{II}+\mathrm{I}+\mathrm{S})$ amplitude-depth variation. $A$ : Rayleigh waves of 0.10 sec period. B: Rayleigh waves of 0.15 sec period. $C$ : body waves, equation [2]. Crosses: average values $(\mathrm{H}+\mathrm{I}+\mathrm{S})$.

The amplitude-depth variation for the vertical component of Rayleigh waves on a homogeneous half-space (Bullen 1963, p. 90) was calculated for wave periods of $0.05,0.10$ and 0.15 sec assuming a shear-wave velocity of $3.5+\mathrm{km} / \mathrm{sec}$. The two latter curves are shown in Fig. 4.

For body-wave propagation we can write the relation between amplitude $a$ and distance $x$ from the source as

$$
a=a_{o} \frac{e^{-k \cdot x}}{x^{n}}
$$


taking both absorption and geometrical spreading into account. If $d=$ the horizontal distance from the noise source to the mine, then $x=\left(h^{-}+d^{2}\right)^{1 / 2}$. A direct application of [1] to our observed data in a least-square procedure does not lead to meaningful results especially as there are too many unknowns: $a_{o}, k, d$ and $n$.

But if we assume that $d=100 \mathrm{~m}$ (agreeing with the average distance in Table II) and that $n=1$ (spherical spreading of continuous waves), we find the following solution:

$$
a=263 \frac{e^{-0.262 x}}{x}
$$

where the units are $0.1 \mathrm{~m} \mu$ for $a$ and $100 \mathrm{~m}$ for $x$. This curve $(C$ in Fig. 4) shows a remarkably good agreement with the observed data, except in the top $100 \mathrm{~m}$.

The value of $z_{i}$ in equation [2] should not be attached any greater significance. Instead assuming $k=0, d=100 \mathrm{~m}$, we find nearly the same good approximation to the observed data by the following equation:

$$
a=282 \frac{1}{x^{1.56}}
$$

However, eq. [2] is preferable, partly for theoretical reasons, partly because it gives slightly better fit to the observations than [3].

We have in this treatment assumed our measured amplitude $a$ to be identical with the total amplitude, although we measured only the vertical component. This is a permissible assumption, if we consider the possible body waves $(P$ and $S V$ ) and their components. In both cases we find that eq. [1] holds, and that the value of $n$ is approximately unchanged for $P$, but replaced by $n+1$ in case of $S V$. This means that if eq. [2] would correspond to a $P$ wave, then eq. [3] would correspond to an $S V$ wave. The true average may be somewhere between eqs. [2] and [3], but, as mentioned, the numerical range between these two formulas is very small indeed.

Comparing now our observed data with explanations in terms of surface waves or body wares, we can state the following:

1) The curvature found for the $\log a-h$ curve in every individual case camnot be explained by Rayleigh waves but is well explained by body waves, at least for $h>d$. It should be observed that $a$ cannot usually be determined accurately, and that its effective value may often be less than given in Table II. 
2) The average slope of the observed $\log a-h$ curve for greater depths $(h>100 \mathrm{~m})$ agrees roughly with the slope of the colresponding eurve for Rayleigh waves, if these have a period of 0.14 sec. But the average observed period (Table II) is only 0.08 sec, and this is by far too much deviation to reconcile with Rayleigh waves.

3) There is generally a downward propagation of the observed waves, the vertical velocity component being of the order of $5 \mathrm{~km} / \mathrm{sec}$. This also favours a body-wave explanation.

4) If Rayleigh waves are assumed, their wave lengths are between 100 and $420 \mathrm{~m}$. This means that we are located at a distance from the source, which is generally less than one wave length. This is the zone where surface waves are being formed, and no fully developed surface waves are to be expected.

5) In case of both explanations the greatest deviation from the observations is found in the uppermost $100 \mathrm{~m}$. The observed decrease is much more rapid than expected from any theory of homogeneous media. This is also the layer where the greatest variations between the different mines is fomd (Table III).

The remarkably good agreement especially between equation [2] and our observed data makes it superfluous to try other more complicited explanations, such as higher-mode Rayleigh waves, reflections and reverberations of body waves, or a more detailed consideration of the geological structure.

In conclusion, we state that the depth effect we have observed is essentially an effect of the distance from the noise source. However, the observed decrease of noise amplitudes in the uppermost $50 \mathrm{~m}$ is much more rapid than wonld be expected simply from a distance effect and demonstrates clearly the advantage of getting away from the free surface.

\section{ACKNOWLEDGMENTS.}

The research reported in this paper was carried ont at the Seismological Institute, Uppsala, with the sponsorship of the Cambridge Research Laboratories of the Office of Aerospace Research, United States Air Force, through its European Office, as part of the Advanced Research Projects Agency's project Vela-Uniform, under Contract $\triangle \mathrm{F}$ $61(052)-702$. 
The three mines investigated belong to the Stallberg Mining Company. Extremely valuable help was received from Dr. A. Wesslén in planning the field operations and from engineers, technicians and others in the installation of the seismometers and in performing the field work.

The field observations were made by Mr. H. Borg, Mr. C. Lindgren and Mr. E. Husebye.

Dr. B. Jansson contributed by a valuable discussion on the data processing technique.

I like to extend my best thanks to all persons and institutions mentioned.

Seismological Institute, Cppsala, sweden. January, 1966.

\section{REFERENCES}

BÅrI II., Crustal struchure of Iceland. "Jour. Geoph. Res.", 65, 1793-1807, (1960).

B\&ти M., Seisnic recording possibilities in Sweden. Res. Inst. Nat. Defence, Stockholm, Rep. A 4466-4721, 32 pp., 1965.

Broding R.A. and Heare D. P., Evaluation of a pressure detector as a leep well seismometer. Cent. Geophys. Corp. Tulsa, Oklahoma, Rep. P-4-61-2, Contr. AF 19(604)-8454, 20 pp. + 20 figs., 1961.

Bullen K. E., An Introduction to the Theory of Seismology. 381 pp., Cambridge Univ. Press, 1963.

CARDER D.S., The requirements of a high-sensitivity seismograph station. "Vesiac Rep.", 4410-63-X, 64 pp., 1963.

KÁRík V. and Tony is V., Underground measurements of the seismic noise level. "Stud. Geoph. et Geod.", 5, 231-236, (1961).

MaGinusson N. H., Malmgeologi. 439 pp., Jernkontoret, Stockholm, 1953.

Magnusson N.H., Granduxd E. and Lundqvist G., Sveriges geologi. 424 pp., Norstedt, Stockholm, 1949.

Vesiac Stap, Fesiac conference proceedings: Progress of Tela Uniform borehole research. "Vesiac Rep.", \$410-83-X, $167 \mathrm{pp} ., 1964$. 


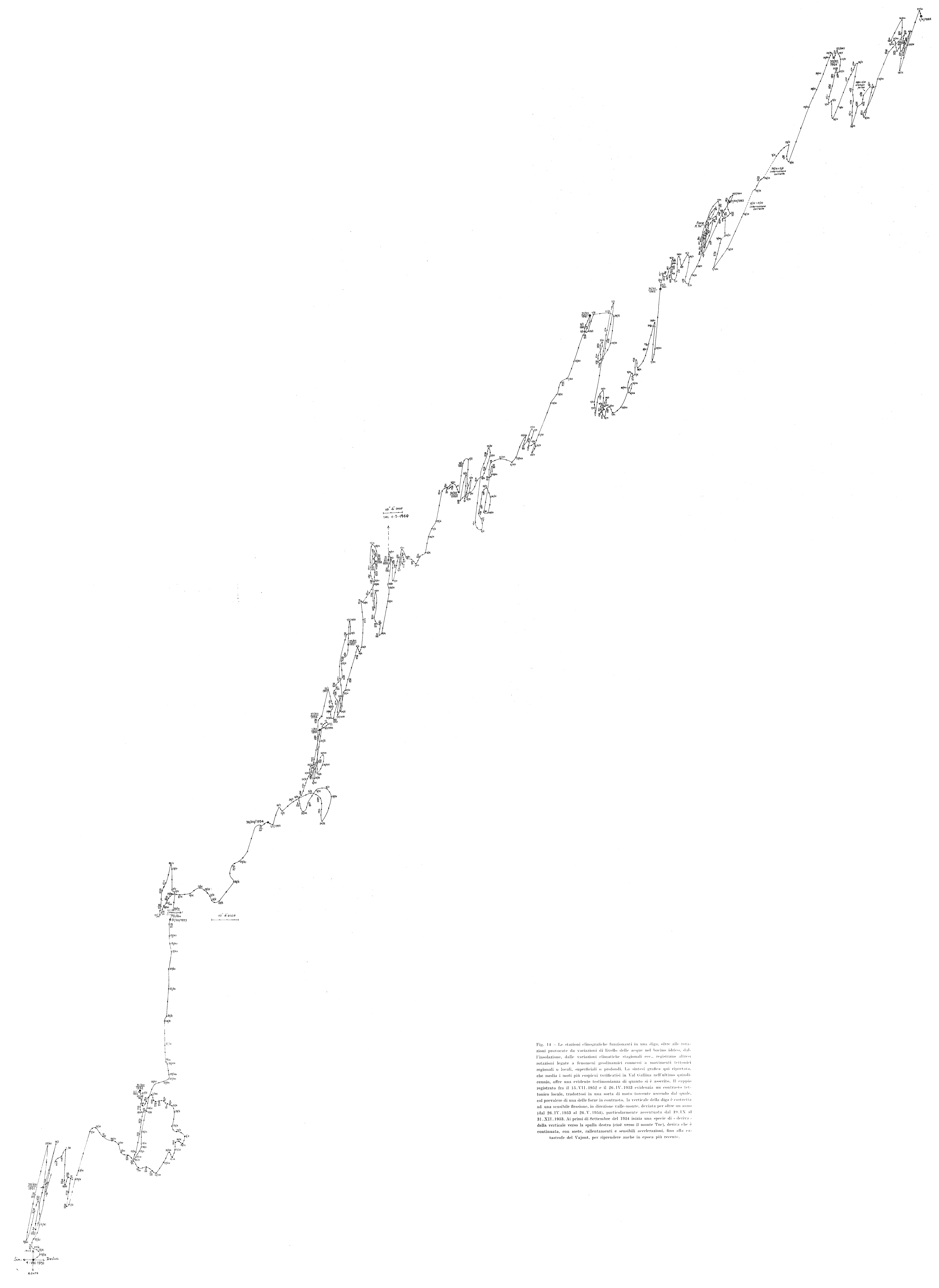

